\title{
Indoor Residual Spraying (IRS) and Its Impact on Malaria Prevalence in West Africa Using the Panel Data Regression Model
}

\author{
Mends-Brew Edwin ${ }^{1}$, Fletcher Afenyi Ernest ${ }^{2}$ \\ ${ }^{1}$ Department of Mathematics and Statistics, Accra Polytechnic, Accra, Ghana \\ ${ }^{2}$ Ghana AIRS Project, Accra, Ghana
}

Email address:

emendsbrew@yahoo.com (Mends-Brew E.), ernestnanaafenyi@yahoo.com (Fletcher A. E.)

\section{To cite this article:}

Mends-Brew Edwin, Fletcher Afenyi Ernest. Indoor Residual Spraying (IRS) and Its Impact on Malaria Prevalence in West Africa Using the Panel Data Regression Model. Science Journal of Applied Mathematics and Statistics. Vol. 4, No. 1, 2016, pp. 12-20.

doi: 10.11648/j.sjams.20160401.12

\begin{abstract}
Malaria remains one of the most important public health concerns across the globe. In 2012 alone, the World Health Organization reported an estimated 207 million cases and associated death of about 670,000 with majority of cases coming from Africa. There have been tremendous efforts at controlling malaria and its related mortality. The two main interventions recommended by the World Health Organization for malaria control and prevention are, Indoor Residual Spraying (IRS) and the use of Insecticides Treated Nets (ITNs). On a limited scope, studies conducted within some communities and limited geographical areas have shown the effectiveness of IRS in reducing the prevalence of the disease. However, not many such studies have looked at the impact of IRS on the prevalence of malaria at the universal level. This paper seeks to evaluate the impact of Indoor Residual Spraying on the prevalence of malaria in West Africa by accounting for the effects of alternative malaria prevention strategies, economic, demographic and funding availability for malaria prevention and control. A panel data for fifteen West African countries from 2008 to 2012 was analyzed. The results showed that for years in which Indoor Residual Spraying was implemented, prevalence of malaria reduced by $71 \%$ compared to periods preceding the implementation of Indoor Residual Spraying. This paper further established that ITN coverage, funding availability for Malaria intervention and gross domestic product have a significant negative impact on the prevalence of Malaria while population and the combination of Indoor Residual Spraying and ITN have a significant positive impact on the prevalence of the disease. Indoor Residual Spraying and its impact on the prevalence of Malaria were observed to be higher than the impact of ITN coverage on the prevalence of the disease. These findings are relevant for policy direction regarding the continuance of Indoor Residual Spraying implementation especially in the post 2015 agenda for malaria control and prevention.
\end{abstract}

Keywords: Malaria, Indoor Residual Spraying (IRS), Insecticide Treated Nets (ITN), Prevalence Rate, Panel Data Regression

\section{Introduction}

According to the Centre for Disease Control and Prevention (CDC), malaria is a serious and sometimes fatal disease. It is a mosquito-borne infectious disease of humans and other animals that is caused by parasitic protozoans. It is transmitted by the bite of an infected female Anopheles mosquito. Symptoms of malaria typically include fever and headache, which in severe cases can progress to coma or death.

Malaria remains the single most important parasitic disease causing major public health problems across the globe. According to the World Health Organization's (WHO) estimates released in 2013, about 207 million cases of Malaria were reported in 2012 causing an estimated 627, 000 deaths (World Health Organization, 2014). Though there is an overwhelming evidence of the incidence of malaria around the world, WHO reports confirm that people living in the poorest countries are the most vulnerable to the disease. It causes widespread premature death and suffering especially in children, imposes financial hardship on poor households, and holds back economic growth and improvements in living standards in some countries 
especially in Sub-Saharan Africa (Orem et al. 2012) [13]. In $2010,81 \%$ of reported malaria cases and $90 \%$ of malaria deaths occurred in the African region (World Health Organization, 2011). Similarly, in 2012, 85\% of malaria cases and $90 \%$ of malaria deaths occurred in the African Region, mostly among children under 5 years of age and pregnant women (World Health Organization, 2014). Although malaria remains a deadly disease, illness and death from malaria are preventable.

\subsection{Malaria Prevention and Control Strategies}

Prevention of malaria involves protecting people against mosquito bites and taking anti-malarial medicines. To effectively achieve this, the Global Malaria Programme from the WHO (World Health Organization, 2006) has recommended the following three basic interventions for malaria control: (1) Diagnosis of malaria cases and treatment with Artemisinin-based Combination Therapy (ACTs), (2) Distribution of Insecticide-Treated Nets (ITNs) to achieve full coverage of populations at risk of malaria and (3) Implementation of Indoor Residual Spraying (IRS) with the approval to use DDT.

Insecticides Treated Nets and Indoor Residual Spraying are considered to be vector control interventions that are aimed directly at targeting the malaria causing mosquito. According to the WHO, the scale up, high coverage and sustained implementation of insecticides nets distribution and implementation of Indoor Residual Spraying will go a long way to achieve global malaria goals.

\subsection{Indoor Residual Spraying (IRS) for Malaria Control}

Indoor Residual Spraying (IRS) is one of the two main malaria vector control interventions recommended by the WHO. Together with ITNs they account for almost $60 \%$ of global investment in malaria control (World Health Organization, 2013) [22]. IRS is the application of insecticides to the inside walls of sleeping rooms and other surfaces that serve as resting places for Malariainfected mosquitoes. Primarily, IRS works by reducing the life span and density of the Malaria vector. In some cases, it also acts by repelling mosquitoes from entering houses thus reducing the vector contact with humans and therefore preventing Malaria transmission (World Health Organization, 2006) [23].

Over the years, IRS has been implemented in many parts of the world as part of the fight against Malaria. In 2012, a total of 88 countries, including 40 countries in the African Region, implemented Indoor Residual Spraying for malaria control (World Health Organization, 2013) [22]. Countries in West Africa that have a history of Indoor Residual Spraying implementation include Ghana, Nigeria, Mali, Benin and Liberia (AFM, 2007), (World Health Organization, 2007) [21].

Since its inception after many years, Indoor Residual Spraying still remains a powerful vector control tool for reducing and interrupting malaria transmission and protecting people from Malaria. In 2012, 135 million people ( $4 \%$ of the global population at risk of malaria) were protected by Indoor Residual Spraying worldwide. In Africa, the proportion of the population at risk protected by Indoor Residual Spraying rose from less than $5 \%$ in 2005 to $11 \%$ in 2010, but fell to $8 \%$ in 2012 due to cost of non-pyrethroid insecticides (World Health Organization, 2013) [27].

Indoor Residual Spraying has been funded around the world and especially in Africa by the Global Fund to Fight AIDS, TB and Malaria, Roll Back Malaria Partnership, World Health Organization, World Bank, United Nations Children's Fund and the United States Agency for International Development (USAID) through the President's Malaria Initiative (PMI). In September 2014, USAID awarded ABT Associates a 3-year contract to implement IRS in fifteen African countries to help reduce the scourge and burden of Malaria. This is expected to reach about 27 million people by 2017 .

Historically, IRS has significantly reduced malaria transmission in many locations worldwide; however more evidence is needed to guide future policy direction and the extensive implementation of IRS across the globe.

\subsection{IRS and Malaria Prevalence Rates}

The impact of malaria control interventions on the prevalence of malaria and in particular the impact of IRS on the prevalence of Malaria remains one of the most published in the field of Public Health and Health Economics. In a literature search and meta-regression analysis, it was found that there were over 400 published articles between 2000 and 2012 on the subject of the impact of IRS on the prevalence of Malaria (Kim, Fedak, \& Kramer, 2012) [10].

Some studies have evaluated the impact of IRS with particular types of insecticides on the prevalence of Malaria. After following 22 IRS villages and 22 non-IRS villages in East Shoa of Ethiopia from 1999 to 2002, the work of (Hamusse, Balcha \& Belachew, 2012) [5] demonstrated that IRS with DDT was effective in reducing the prevalence of malaria in the IRS villages compared to the non-IRS villages. They also found that even among the IRS villages, the prevalence of malaria was significantly lower during the post-IRS period (2001 to 2002) than the pre-IRS period (1999 to 2000). Similar findings were made by (Kim et al., 2012) [10] when they conducted a metaanalysis on different studies that had evaluated the impact of IRS on the prevalence of malaria. In some parts of Uganda, IRS was associated with a significant reduction in malaria morbidity in an area of high transmission intensity and the benefits appeared to be greatest after switching to a carbamate class of insecticides. This was discovered after analysis of routine data collected on more than 90,000 patient visits at a single health facility over a 56 month period covering five rounds of IRS using three different types of insecticides (Kigozi, et al., 2012).

Some studies have also tried to quantify the impact of IRS alone on the prevalence of malaria and compared it to the impact of IRS and ITN on the incidence of malaria. Findings 
of such studies have had different conclusions. Some have found that there is a significant added effect for using IRS and ITNs while others have also found that there is no significant added effect (World Helath Organization, 2014). In some cases, it was found that, the impact of IRS, ITN or a combination of both on the prevalence of malaria depends on whether or not malaria transmission is high, medium or low. Fullman et al. (2013) [2] studied the effectiveness of IRS and ITN on malaria parasitaemia in children under five years across seventeen Sub-Saharan African countries and found that living in households with both ITNs and IRS was associated with a significant risk reduction against parasitaemia in medium (53\% to $67 \%$ ) and high transmission areas $(31 \%)$, than living in households with either IRS or ITN alone. For low transmission areas, they found that having both ITNs and IRS was not significantly more protective against parasitaemia than either intervention alone. (Pluess et al. 2010) [14] also found evidence from randomized comparisons of IRS versus no IRS that IRS reduces malaria prevalence in relatively stable malaria transmission areas. They also found that in comparing the impact of IRS and ITN, ITN appeared to offer better protection in unstable transmission areas than in stable transmission areas. However, they concluded that randomized trial data from stable malaria areas is very limited to generalize their conclusion. On the other hand, a review of current evidence on combining Indoor Residual Spraying and ITNs conducted by WHO has shown that, there are evidence from random trials in Benin and other part of Africa that there is no significant benefit for reducing malaria morbidity, infection and transmission when combining Indoor Residual Spraying and ITNs (World Helath Organization, 2014) [28].

\section{Data}

The data used for this study were obtained from World Health Organization's (WHO) World Malaria Reports (WMR) and the International Monetary Fund's (IMF) World Economic Outlook (WEO) data set.

Data in the annexes of the 2010 and 2013 WMR reports were used for all analysis. Data on ITN and IRS coverage from 2008 and 2009 were obtained from annex 5 of the WMR 2010. Data for ITN and IRS coverage for 2010, 2011 and 2012 were obtained from annex 4 of the WMR 2013.

Data on Funding for malaria interventions for the fifteen West African countries from 2008 to 2012 were obtained from annex 3 of the WMR 2013.

Gross Domestic Product (GDP) and population figures for the fifteen West African countries were obtained from the International Monetary Fund (IMF) data set on World Economic Outlook (WEO).

The country GDP data used for the analysis in this study were GDP at current prices (from 2008 to 2012). Population data in the same data set for the fifteen West Africa countries from 2008 to 2012 were used for the analysis.

\section{Methodology}

This paper seeks to evaluate the impact of Indoor Residual Spraying on the prevalence of malaria in Sub Saharan Africa taking into account alternative malaria prevention strategies, economic factors, demographic factors and funding availability for malaria prevention. The characteristics of the data set informed the choice of the analytical model for the analysis of data. The data set consist of fifteen West African countries. For each country, six variables; (number of reported malaria cases, whether or not the country is implementing IRS, the percentage coverage of ITN among population at risk of malaria, the estimated total population, gross domestic product and the level of donor funding for malaria related interventions) were recorded for each year from the year 2008 to the year 2012. Data from 2008 to 2012 were used because prior to 2008, most countries were not consistent with their data reporting on the variables of interest in this paper. However, consistent data reporting commenced in 2008. Panel data was used for the analysis. This data set consists of observations for fifteen countries (cross sectional) over a time period (time series). Data that exhibits both cross section and time series characteristics are panel data and are best analyzed within the panel data regression models framework (Katchova, Panel Data Models, 2013) [9].

\subsection{Panel Data Regression Model}

Typically, there are two main types of Panel Models that can be used to analyze panel data. Fixed Effect Models and Random Effect Model (Katchova, 2013) [9], (Hill et al. 2011) [6]. The Fixed Effect Model was used because the data set was relatively short and wide. The time series interval ( $T$ $=2008-2012=5$ years $)$ is less than the number of countries $(N=15)$, hence $T<N$. For such short and wide panel data (Hill, Griffiths, \& Lim, 2011) [6], the use of the Panel Data Fixed Effect Model is highly recommended.

Fixed-Effects Models make less restrictive assumptions than random-effects models. For example, Fixed-Effects Models allow unobservable variables to have whatever associations with the observed variables and the individuals over time act as their own controls (Allison, 2009) [1].

The general panel model with fixed effects is given as follows:

$$
y_{i t}=\mu_{t}+\beta X_{i t}+\gamma Z_{i}+\alpha_{i}+\varepsilon_{i t}
$$

- $y_{i t}$ is the dependent variable that is linearly dependent on a set of predictor variables

- $\mu_{t}$ is an intercept term that can be different for each time period but does not vary across individuals.

- $X$ stands for the independent variables whose values can vary across time and individuals.

- Z stands for the independent variables whose values do not change across time but can change from individual to individual. These are time-invariant values.

- $\beta$ and $\gamma$ are the coefficients for the Xs and Zs. These effects are time-invariant, 
- $\alpha_{i}$ and $\varepsilon_{i t}$ are both error terms. $\varepsilon_{i t}$ is different for each individual at each point in time. $\alpha_{i}$ only varies across individuals but not across time. We can think of $\alpha_{i}$ as representing the effects of all the time invariant variables that have not been included in the model.

The major assumptions that the study makes in using the fixed effects model are that:

- Individual error terms, $\alpha_{i}$ is correlated with the explanatory variables $\left(X_{S}\right)$ so that the effect of timeinvariant variables that are not included in the model can be controlled.

As indicated by (Allison, 2009) [1], an advantage of the fixed effect model when applied to panel data is that it can adequately control for time invariant unobserved and omitted variables, which are a problem with other regression model. However, Allison (2009) [1] notes that a disadvantage of the fixed effects model is that, though it can be controlled for unobserved time invariant variables, the effects of such variables on the dependent variables cannot be measured.

\subsection{Specification of the Fixed Effect Model for the Prevalence of Malaria}

The following fixed effect model was used for the study:

$$
M a l_{i t}=\beta_{1 i}+\beta_{2} I R S_{i t}+\beta_{3} I T N N_{i t}+\beta_{4} P O P_{i t}+\beta_{5} G D P_{i t}+\beta_{6} F U N D_{i t}+\beta_{7} \operatorname{IRSITN}_{i t}+\varepsilon_{i t}
$$

Where:

- $\beta_{1}=$ denotes the estimates of individual country specific constants, or fixed effects that cannot be observed, but causes each country to be different.

- $\beta_{2}=$ coefficient for the impact of indoor residual spraying on prevalence of malaria

- $\beta_{3}=$ coefficient for the impact of ITN coverage on prevalence of malaria

- $\beta_{4}=$ coefficient for the impact of population size on prevalence of malaria

- $\beta_{5}=$ coefficient for the impact of gross domestic product on prevalence of malaria

- $\beta_{6}=$ coefficient for the impact of donor funding on prevalence of malaria

- $\beta_{7}=$ coefficient for the impact of the interactive effect of combining indoor residual spraying and ITN coverage on prevalence of malaria

- $\varepsilon_{i t}=i s$ the error term that captures the impact of all other relevant variables that may have been omitted.

A description of the model's variables is provided below:

\subsubsection{Nature of Dependent Variable (Mal) and Model Selection}

The variable of interest in this study is the prevalence of malaria. This variable refers to the actual count of the number of malaria cases that were reported in each of the fifteen countries in each year from 2008 to 2012. Data on the number of malaria cases from 2008 to 2012 was obtained from the annex of the WMR 2013 and used for analysis.

The nature of the number of reported malaria cases, Mal, makes it a special variable that needs special treatment in a regression model. Mal can only take on values from $0,1,2$, $3,4 \ldots . n$ in any given year for any of the fifteen countries under consideration. Such variables are usually analyzed within the framework of count data models using the Poisson probability distribution function (Katchova, 2013) [8].

The Poisson distribution is a discrete probability distribution for the counts of events that occur randomly in a given interval of time (in this case yearly; from 2008 to 2012). With reference to (Hill, Griffiths, \& Lim, 2011) [6] if we let $\mathrm{Mal}=$ the number of malaria cases in a given year, then, if the average number of malaria cases per year is $\lambda$, the probability of observing $\mathrm{m}$ malaria cases in a given year is given by:

$$
\begin{aligned}
& \boldsymbol{f}(\boldsymbol{y})=\boldsymbol{P}(\mathrm{Mal}=\boldsymbol{m})=\frac{e^{-\lambda} \lambda^{m}}{\boldsymbol{m} !}, \text { for values of } m \text { from } 0,1,2,3, \ldots n \\
& e=\text { constant of natural logarithm }
\end{aligned}
$$

This Poisson probability function has one parameter, $\lambda$, which is the average (and variance) of Mal so that the expected value of $M a l$ is equal to the variance of $M a l: E(M)$ $=\operatorname{Var}(M)=\lambda$.

To be able to model a count data within the panel regression framework, STATA's procedure for Panel Poisson regression model with fixed effects was used.

\subsubsection{The Independent Variables}

Below is the description of each of the independent

\begin{tabular}{|c|c|c|c|}
\hline Variable & Description & Measurement & Apriori (+/-) \\
\hline IRS & $\begin{array}{l}\text { Indoor Residual Spraying, IRS is one of the } \\
\text { recommended interventions for Malaria control } \\
\text { by the WHO and has been used by some } \\
\text { countries for some time now. }\end{array}$ & $\begin{array}{l}\text { This is a dummy variable. It assumes } \\
\text { the value of } 1 \text { for years in which } \\
\text { Indoor Residual Spraying was } \\
\text { implemented by a country. It assumes } \\
\text { the value of } 0 \text { for years in which a } \\
\text { country did not implement Indoor } \\
\text { Residual Spraying. }\end{array}$ & $\begin{array}{l}\text { Negative relationship. I expect malaria } \\
\text { prevalence to reduce where there is the } \\
\text { implementation of IRS and expect malaria } \\
\text { prevalence to increase where there is no } \\
\text { implementation of IRS. }\end{array}$ \\
\hline
\end{tabular}
variables that were used in the model.

Table 1. Description of Independent Variables. 


\begin{tabular}{|c|c|c|c|}
\hline Variable & Description & Measurement & Apriori (+/-) \\
\hline & $\begin{array}{l}\text { worldwide including } 34 \text { countries in Africa had } \\
\text { adopted the WHO recommendation to provide } \\
\text { ITNs to all persons at risk of malaria and an } \\
\text { estimated total of about } 145 \text { million ITNs were } \\
\text { distributed in } 2013 \text { alone. }\end{array}$ & $\begin{array}{l}\text { persons, but allowing for only one } \\
\text { person sleeping under some ITNs in } \\
\text { households with an odd number of } \\
\text { inhabitants) divided by the population } \\
\text { at high risk of malaria. }\end{array}$ & \\
\hline$G D P$ & $\begin{array}{l}\text { GDP remains one of the widely used measures } \\
\text { of the strength of an economy and the living } \\
\text { standards of the people of a nation. This is the } \\
\text { measure of the aggregate output of the } \\
\text { economy include: personal consumption; } \\
\text { government expenditure, private investment, } \\
\text { capital, and net exports (i.e. exports minus } \\
\text { imports). }\end{array}$ & $\begin{array}{l}\text { GDP at current prices (from } 2008 \text { to } \\
\text { 2012) which are based on actual GDP } \\
\text { in national currency provided by the } \\
\text { national statistics unit/ department of } \\
\text { each of the fifteen countries were } \\
\text { converted to U. S. dollars using } \\
\text { market exchange rates (yearly } \\
\text { average). This variable is measured in } \\
\text { billions of United States dollars (\$). }\end{array}$ & $\begin{array}{l}\text { A negative relationship is expected between } \\
\text { malaria prevalence and GDP. As GDP improves, } \\
\text { it is expected that per capita income will increase } \\
\text { and people will live better lives which will } \\
\text { include accessing better health cars services. This } \\
\text { will lead to a decrease in the prevalence of } \\
\text { malarial. If GDP declines, per capita income will } \\
\text { also reduce and many people will not be able to } \\
\text { live better lives and afford good health care } \\
\text { services, this will lead to increase in the } \\
\text { prevalence of malaria. }\end{array}$ \\
\hline$P O P$ & $\begin{array}{l}\text { This refers to the total population of a country. } \\
\text { The data is based on the latest national } \\
\text { population and housing census for each } \\
\text { country and consists of a count of all persons } \\
\text { falling within the scope of the census. This } \\
\text { data is obtained from each country's Statistical } \\
\text { Unit. For years where there was no census, } \\
\text { estimates are provided based on history of the } \\
\text { population growth of the country. }\end{array}$ & $\begin{array}{l}\text { This variable is measured in millions } \\
\text { of persons and is the count of the } \\
\text { number of people living in particular } \\
\text { country in a particular year. }\end{array}$ & $\begin{array}{l}\text { A positive relationship is expected between } \\
\text { population and prevalence of malaria. As } \\
\text { population increases, the population at risk of } \\
\text { malaria will also increase and eventually lead to } \\
\text { an increase on the prevalence of malaria. On } \\
\text { other hand, if population size decreases, the } \\
\text { population at risk of malaria will decrease and } \\
\text { eventually, the prevalence of malaria will also } \\
\text { decrease. }\end{array}$ \\
\hline FUND & $\begin{array}{l}\text { This is the total amount of donor monies } \\
\text { available to each country that is specifically } \\
\text { earmarked for malaria related interventions. } \\
\text { The data used for analysis are those reported } \\
\text { by the by external donors and does not include } \\
\text { each country's Government funding. }\end{array}$ & $\begin{array}{l}\text { This variable is measured in millions } \\
\text { of United Sates dollars. The level of } \\
\text { funding available for each country } \\
\text { was obtained from annex } 3 \text { of the } \\
2013 \text { World malaria report. For the } \\
\text { purposes of this study, the amounts } \\
\text { reported in annex } 3 \text { of the WMR } 2013 \\
\text { were scaled down by dividing by } \\
1,000,000 \text {. }\end{array}$ & $\begin{array}{l}\text { A negative relationship is expected between } \\
\text { malaria prevalence and FUND. As Funding for } \\
\text { malaria related interventions increases, it is } \\
\text { expected that multiple interventions can be } \\
\text { carried out simultaneously towards controlling } \\
\text { malaria and this will lead to a decrease in the } \\
\text { prevalence of malaria. On the other hand, if the } \\
\text { level of funding for malaria related interventions } \\
\text { reduces, efforts to fight malaria will dwindle and } \\
\text { prevalence of malaria will rise. }\end{array}$ \\
\hline IRSITN & $\begin{array}{l}\text { This refers to the combination of IRS } \\
\text { implementation and ITN coverage. }\end{array}$ & $\begin{array}{l}\text { This is an interaction variable between } \\
I R S \text { and } I T N \text { coverage was generated } \\
\text { and included in the model. The } \\
\text { interaction variable IRSITN was } \\
\text { generated by multiplying the indoor } \\
\text { residual spraying variable }(I R S) \text { by the } \\
\text { ITN coverage variable }(I T N) \text { for each } \\
\text { year, so } I R S I T N=I R S * I T N\end{array}$ & $\begin{array}{l}\text { A negative relationship is expected. Both IRS } \\
\text { and ITN coverage are preventive interventions. It } \\
\text { is expected that when IRS is implemented and } \\
\text { ITN coverage is also increased to reach more } \\
\text { population at risk of malaria, "double protection" } \\
\text { is given and it is expected that the prevalence of } \\
\text { Malaria will decrease. We will also expect } \\
\text { prevalence of malaria to decrease in the absence } \\
\text { of either or both interventions. }\end{array}$ \\
\hline
\end{tabular}

\section{Findings and Discussion}

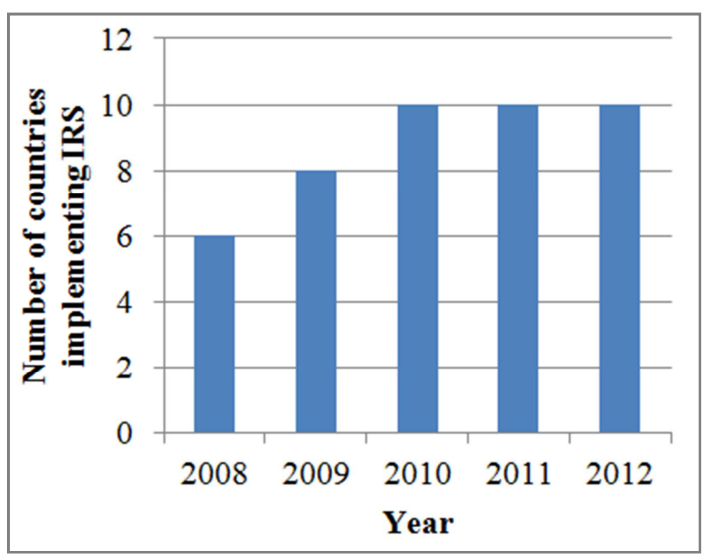

Figure 1. Number of West African countries implementing IRS form 2008 to 2012.
The number of countries implementing IRS increased from 6 in 2008 to 10 by 2012 as illustrated in figure 1 . It is evident that some countries did not implement Indoor Residual Spraying at all over the period. On the contrary, a number of countries under consideration implemented Indoor Residual Spraying each year from 2008 to 2012.

Countries like Côte d'Ivoire, Guinea-Bissau and Togo did not implement Indoor Residual Spraying at all from 2008 to 2012. Gambia, Burkina Faso, Gambia and Niger had implemented Indoor Residual Spraying at least twice between 2008 to 2012, whilst countries like Benin, Ghana, Liberia and Mali implemented Indoor Residual Spraying each year from 2008 to 2012.

Table 2 provides descriptive statistics for all the variables used in the study. The mean values, standard deviations (overall, between and within), minimum and maximum values are presented. Average number of reported Malaria cases from 2008 to 2012 across the fifteen countries was 
$2,057,934$ cases per annum. The minimum number of reported Malaria cases was 140,143 cases per year and the maximum number of reported Malaria cases was 10,700,000 cases per year. Values of the standard deviations show that there were more variations in the number of reported malaria cases between countries than reported within each country.

Averagely, $48.56 \%$ of the population at risk of malaria across the fifteen countries was covered by the use of ITNs between 2008 and 2012. But this varied from 2\% (minimum) to $100 \%$ (maximum). Overall, average GDP from 2008 to 2012 was $\$ 23$ billion and varied between $\$ 0.82$ billion to $\$ 264.2$ billion over the period. Between countries, there was a significant variation in GDP than within countries.

The probability that a country will implement IRS in any year is approximately 0.59 . Implementation of IRS between countries showed more variability than within countries. This suggests that countries that implemented IRS in any year were more likely to continue implementing IRS than countries that have not implemented IRS.

Between countries, GDP varied by some $\$ 56.53$ billion but varied by only $\$ 8.62$ billion within countries. An average of $\$ 26.10$ million donor funding was available for the implementation of malaria interventions. This amount varied from $\$ 0.00$ million for years in countries where donor funding was not available for malaria related interventions (example in Côte d'Ivoire, 2008 and Mauritania, 2011 and 2012) to $\$ 319.07$ million. Between countries, donor funding varied by some $\$ 35$ million and varied by some $\$ 27.27$ million within individual countries. Population variations were observed to be significant between countries $(38.25$ million) than within individual countries (1.63 million). The average population was 20.22 million and varied from 1.45 million to 165.75 million.

Table 2. Summary statistic for Dependent and Independent Variables.

\begin{tabular}{|c|c|c|c|c|c|}
\hline Variable & Mean & Variation & Standard deviation & Minimum & Maximum \\
\hline \multirow{3}{*}{ Mal } & \multirow{3}{*}{$2,057,934$} & Overall & $1,999,339$ & 140,143 & $10,700,000.00$ \\
\hline & & Between & $1,761,177$ & $160,128.4$ & $5,209,343.00$ \\
\hline & & Within & $1,031,152$ & $143,011.7$ & $7,619,596.00$ \\
\hline \multirow{3}{*}{ IRS } & \multirow{3}{*}{0.59} & Overall & 0.50 & 0.00 & 1.00 \\
\hline & & Between & 0.41 & 0.00 & 1.00 \\
\hline & & Within & 0.29 & -0.21 & 1.19 \\
\hline \multirow{3}{*}{ ITN Coverage } & \multirow{3}{*}{48.56} & Overall & 28.82 & 2 & 100.00 \\
\hline & & Between & 15.93 & 16.20 & 71.06 \\
\hline & & Within & 24.30 & -3.82 & 102.38 \\
\hline \multirow{3}{*}{ GDP } & \multirow{3}{*}{23.00} & Overall & 55.66 & 0.82 & 264.20 \\
\hline & & Between & 56.53 & 0.86 & 224.77 \\
\hline & & Within & 8.62 & -31.11 & 62.44 \\
\hline \multirow{3}{*}{ Funding } & \multirow{3}{*}{26.10} & Overall & 43.64 & 0.00 & 319.07 \\
\hline & & Between & 35.04 & 0.48 & 142.90 \\
\hline & & Within & 27.27 & -72.22 & 202.27 \\
\hline \multirow{3}{*}{ Population } & \multirow{3}{*}{20.22} & Overall & 37.23 & 1.45 & 164.75 \\
\hline & & Between & 38.25 & 1.52 & 156.17 \\
\hline & & Within & 1.63 & 11.87 & 28.81 \\
\hline \multirow{3}{*}{ IRSITN } & \multirow{3}{*}{32.95} & Overall & 35.75 & 0.00 & 100.00 \\
\hline & & Between & 26.17 & 0.00 & 64.53 \\
\hline & & Within & 25.10 & -27.05 & 86.78 \\
\hline
\end{tabular}

Table 3. Poisson panel regression estimates (Number of reported malaria cases is the independent variable).

\begin{tabular}{|c|c|c|c|c|c|c|}
\hline \multirow{2}{*}{ Variable } & \multirow{2}{*}{ Coefficient/ marginal effect } & \multirow{2}{*}{ Std. Error } & \multirow{2}{*}{ t-value } & \multirow{2}{*}{ p-value } & \multicolumn{2}{|l|}{$95 \%$ CI } \\
\hline & & & & & lower & Upper \\
\hline$I R S$ & $-0.7132 *$ & 0.000448 & -1590.73 & 0.0000 & -0.71407 & -0.71231 \\
\hline$I T N$ & $-0.0032 *$ & 0.000008 & -407.03 & 0.0000 & -0.00321 & -0.00318 \\
\hline$G D P$ & $-0.0157^{*}$ & 0.000030 & -528.19 & 0.0000 & -0.01580 & -0.01568 \\
\hline Funding & $-0.0002 *$ & 0.000005 & -43.33 & 0.0000 & -0.00023 & -0.00021 \\
\hline Population & $0.1287 *$ & 0.000154 & 835.81 & 0.0000 & 0.12841 & 0.12902 \\
\hline IRSITN & $0.0129 *$ & 0.000009 & 1419.43 & 0.0000 & .0128796 & 0.01292 \\
\hline$N$ & & 75 & & & & \\
\hline Groups & & 15 & & & & \\
\hline Observations per group & & 5 & & & & \\
\hline Wald $\operatorname{chi}^{2}(6)$ & & 9650000 & & & & \\
\hline Prob $>c h i^{2}$ & & 0.0000 & & & & \\
\hline
\end{tabular}

\footnotetext{
* = significant at 0.05 level
} 


\subsection{Impact of Indoor Residual Spraying on the Prevalence of Malaria}

In determining the impact of indoor residual spraying on the prevalence of malaria, the panel Poisson regression model was used. Specifically, STATA's XT Poisson regression procedure was used in the estimation of equation (1) under section 3.2. The result of the wild test $\left(\right.$ Wald $_{\text {chi }}{ }^{2}=$ 9650000, $P r o b>c h i^{2}=0.0000$ ) shows that all these variables were significant in the model.

The results of the Poisson Panel Regression based on equation (1) are presented in Table 3. The regression results show that implementation of Indoor Residual Spraying has a negative and significant impact on the number of reported malaria cases (prevalence of malaria).

Assuming that all other variables remain unchanged, implementing Indoor Residual Spraying reduces the expected prevalence of malaria by 71.32 percent compared to periods where Indoor Residual Spraying was not implemented.

Indoor Residual Spraying is considered to be one of the most promising technologies for achieving reductions in the global malaria scourge and its burden. Implementing IRS directly targets mosquitoes, especially the female anopheles mosquito, the main carrier of the parasite that causes malaria.

When sleeping rooms are sprayed with WHO approved insecticides, mosquitoes that bite and land on the sprayed surfaces, also pick up lethal doses of the insecticides and eventually die. Once dead, mosquitoes are unable to transmit the malaria causing parasites from one individual to another. As the life span of the mosquitoes is shortened, transmission of the malaria parasites decreases and eventually, prevalence of malaria ultimately decreases. The results of this study show that IRS is significantly effective in decreasing the prevalence of malaria by approximately $71 \%$. This result is consistent with what (Hamusse et al. 2012) [5] found in Ethiopia when they analyzed data from 22 IRS and 22 nonIRS districts. The findings from this study are a universal confirmation of the impact of IRS that has been recorded in single communities or over entire geographical areas.

\subsection{Impact of Other Independent Variables on the Prevalence of Malaria}

Apart from IRS, other variables were found to have significantly impacted on the prevalence of malaria. ITN Coverage, Gross domestic product, Funding availability for malaria interventions and population size all had significant impact on the prevalence of malaria.

A one percent increase in ITN coverage for the population at risk of malaria significantly reduces the expected number of reported malaria cases by 0.32 percent. Also, for every one $\$ 1$ billion increase in gross domestic product, prevalence of malaria decreases by 1.57 percent if all other variables remain unchanged. Similarly, increasing donor funding for the implementation of malaria control programmes by $\$ 1$ million is expected to decrease the prevalence of malaria by
0.02 percent if the impact of all other variables remains unchanged. If all other variables in the model are kept constant and there is an increase of one million residents in the size of a country's population, the prevalence of malaria will also increase by 12.87 percent. Finally, combining Indoor Residual Spraying and ITN increased the prevalence of malaria by 1.29 percent keeping other variables constant.

According to the WHO, the use of ITNs is considered to be one of the most promising technologies for achieving reductions in the global malaria scourge and its burden. The results of this study show that ITN coverage is significantly effective in decreasing prevalence of malaria by approximately $32 \%$. Sleeping under ITNs offers protection for individuals by limiting contacts with mosquitoes that carry the malaria parasites. If a greater proportion of the population at risk of malaria sleep under ITNs, only a small proportion of the population will be exposed to contact with mosquitoes. This will eventually decrease the prevalence of malaria. On the other hand, if ITN coverage is low, then a greater proportion of the population at risk will be exposed to contact with mosquitoes. This will increase the risk of parasite transmission and eventually increase the prevalence of malaria.

The study found that there is a negative and significant relationship between the size of GDP and the prevalence of malaria. This finding is similar to the findings from the work of (Orem et al. 2012) [13], who established that in Uganda, there is a negative relationship between GDP and the prevalence of malaria such that increases in malaria prevalence significantly led to a reduction in the size of GDP through a reduced labour force that leads to low productivity and hence lower outputs yielding lower GDP.

According to the finding in this study, increase in the size of GDP leads to reduction in the prevalence of malaria by 1.57 percent. Increase in GDP may lead to decrease in malaria prevalence through improved wellbeing. From economic theory, increase in GDP can lead to a corresponding increase in the per capita income of the populace. With improved wellbeing, citizens can afford better health services, afford to live in cleaner environments and communities and possibly invest in other forms of malaria prevention without waiting on government to provide such services.

This study has showed that malaria prevalence decreases by approximately $0.02 \%$ for every $\$ 1$ million increase on donor funding for malaria related interventions. This indeed echoes WHO's call to increase funding levels to malaria endemic areas in order to sustain the achievement that have been made so far and also to win the war on malaria. Funding and donor funding for that matter is a key component of the budget of many African countries. Availability of funds earmarked for malaria related interventions, will go a long way to improve the implementation of useful interventions to help fight malaria. This point was emphasized by the WHO in their WMR 2013. WHO indicated that funding has contributed massively to the 
successes that have been made so far in the fight against malaria but noted that funding for malaria intervention is still below what is expected.

Finally, this paper further established that population size of a country has a significant positive relationship with the prevalence of malaria. The impact of non-climatic factors on the prevalence of malaria was discussed by (Kumar \& Reddy, 2014) [11]. Increases in population size and eventually movement of people have contributed to the spread of malaria. As earlier indicated, this study has found that increases in population size are significantly associated with almost $13 \%$ increase in the prevalence of malaria. As population increases, the population at risk of malaria also increases and therefore, more and more people become at risk. Unfortunately, it will be difficult to have policies to control population growth. It was also observed that, across the 15 countries considered in this study, less than $50 \%$ of population at risk of malaria is protected by ITNs. It is clear that intervention coverage is very low and therefore increasing this coverage towards the population at risk will go a long way to help control the prevalence of malaria.

\subsection{Implementing IRS and Use of ITNS}

According to the WHO, recent reductions in the prevalence of the malaria menace have come at a time when there is a massive scale-up of Indoor Residual Spraying and the distribution of ITNs as vector control measures for malaria control and prevention especially in sub-Saharan Africa. ITNs and Indoor Residual Spraying are expected to provide effective malaria transmission control. Over the years, there have been conflicting evidence about whether it is more beneficial to provide both interventions or to implements either one of them. In a randomized trial in Tanzania, (West, et al., 2014) [17] it was found that IRS in combination with ITNs gives significant added protection against malarial infections compared to ITN use alone. Indeed, previous works including the works of (Fullman et al. 2013) [2] also came to a similar conclusion based on evidence from randomized trials. However, randomized trials from other countries like Benin have suggested that the combination of Indoor Residual Spraying and ITN does not offer any added protection from malaria than when either of them is implemented (World Helath Organization, 2014). This study found that IRS can reduce the prevalence of malaria by $71 \%$, and ITN coverage is also associated with a $0.32 \%$ reduction in malaria prevalence while the combined effect of IRS and ITN is associated with increased malaria prevalence by $1.29 \%$. This is not to suggest that combining the two interventions at the same time causes increases in expected number of malaria cases. Since more evidence is still needed as suggested by (Pluess et al., 2010)[14], the conclusion the study makes on this matter is that, there is no evidence, universally that implementing both Indoor Residual Spraying and ITN provides the expected benefit of reducing the prevalence of malaria. Implementing either Indoor Residual Spraying or using ITNs alone significantly reduces the prevalence of malaria than the combination of the two interventions. Also contrary to the conclusion by (Pluess et al 2010) [14] that some limited data have shown ITN as being more effective than IRS, this study shows that IRS is more effective at reducing the prevalence of malaria that ITN coverage.

\section{Conclusion}

Given the global scourge of Malaria, which continues to remain a public health challenge, there is the need to adopt a more pragmatic approach in dealing with this deadly disease. Indoor Residual Spraying has historically showed effectiveness in reducing the prevalence of malaria in some geographical areas. This paper has however, established that at a more comprehensive scale, Indoor Residual Spraying is effective at reducing the prevalence of malaria by $71 \%$ compared to years preceding the implementation of IRS. It also established that ITN coverage, funding available for malaria intervention and gross domestic product have a significant negative impact on the prevalence of malaria while population and the combination of IRS and ITN have a significant positive impact on the prevalence of malaria. Combining IRS and ITN does not yield the projected added protection that is expected compared to using either Indoor Residual Spraying or ITN alone. The impact of IRS on the prevalence of malaria was higher than the impact of ITN coverage on the incidence of malaria. Indoor Residual Spraying has proven to be more effective in reducing the prevalence of malaria, and it is expected that in the coming years, IRS would be adopted by a number of countries as the primary source of malaria control.

As a policy direction especially for the post 2015 MDG deadline, it is suggested that Indoor Residual Spraying will remain the main intervention for malaria control and prevention. This paper has showed that combining Indoor Residual Spraying and ITN coverage does not necessarily provide the added protection that is expected. Therefore, it is better to diversify the use of available funds to implement either Indoor Residual Spraying or the use of ITNs, but not both within the same geographical area.

Further work could be done at a more comprehensive scale on the impact of IRS using panel data from other African countries and also account for the impact of the type of insecticides used for Indoor Residual Spraying. As established by some works conducted by (Hamusse, Balcha, $\&$ Belachew, 2012) [5] the type of insecticides used has the potential to determine the success or otherwise of the IRS on the prevalence of malaria.

\section{References}

[1] Allison, P. D. (2009). Fixed Effects Regression Models. Sage.

[2] Fullman, N., Burstein, R., Lim, S. S., Medlin, C., \& Gakidou, E. (2013). Nets, Spray or Both? The effectiveness of insecticide-treated nets and indoor residual spraying in reducing malaria morbidity and child mortality in sub-Saharan Africa. Malaria Journal, 12 (62). 
[3] Fullman, N., Burstein, R., Lim, S. S., Medlin, C., \& Gakidou, E. (2013). Nets, Spray or Both? The Effectiveness of Insecticide-Treated Nets and Indoor Residual Spraying in Reducing Malaria Morbidity and Child Mortality in SubSaharan Africa. Malaria Journal, 12 (62).

[4] Ghana Statistical Service. (2011). Ghana Multiple Indicator Cluster Survey with an enhanced Malaria Module and Biomarker 2011.

[5] Hamusse, S. D., Balcha, T. T., \& Belachew, T. (2012). The impact of indoor residual spraying on malaria incidence in East Shoa Zone, Ethiopia. Global Action Plan, 5 (11619).

[6] Hill, C. R., Griffiths, W. E., \& Lim, G. C. (2011). Principles of Econometric (4th Ed). John Wiley \& Sons, Inc.

[7] Indoor Residual Spraying of Insecticide and Malaria Morbidity in a High Transmission Intensity Area of Uganda2012PLoS ONE78

[8] Katchova, A. (2013). Count Data Models. Retrieved September 01, 2014, from Econometrics Academy: https://sites.google.com/site/econometricsacademy/econometr ics-models/count-data-models

[9] Katchova, A. (2013). Panel Data Models. (A. Katchova, Producer) Retrieved August 2014, from Econometrics Academy:

https://sites.google.com/site/econometricsacademy/econometr ics-models/panel-data-models

[10] Kim, D., Fedak, K., \& Kramer, R. (2012). Reduction of Malaria Prevalence by Indoor Residual Spraying: A MetaRegression Analysis. The American Journal of Tropical Medicine and Hygiene, 87 (1), 117-124.

[11] Kumar, P., \& Reddy, N. (2014). Factors affecting Malaria disease transmision and incidense: A special focus on Visakhapatnam district. International Journal of Recent Scientific Research, 5 (1), 312-317.

[12] Okumu, F. O., \& Moore, S. J. (2011). Combining indoor residual spraying and insecticide-treated nets for malaria control in Africa: a review of possible outcomes and an outline of suggestions for the future. Malaria Journal, 10 (208).

[13] Orem, J. N., Kirigia, J. M., Azairwe, R., Kasirye, I., \& Walke, O. (2012). Impact of malaria morbidity on gross domestic product in Uganda. International Archives of Medicine, 5 (12).

[14] Pluess, B., Tanser, F. C., Lengeler, C., \& Sharp, B. L. (2010). Indoor residual spraying for preventing malaria. Cochrane Database of Systematic Reviews (4).

[15] PMI|Africa IRS (AIRS) Project Indoor Residual Spraying
(IRS 2) Task Order Four. (2013). Ghana End of Spray Report. Abt Associates Inc, Bethesda, MD.

[16] Principles of Econometrics2011John Wiley \& Sons, Inc

[17] West, P. A., Protopopoff, N., Wright, A., Kivaju, Z., Tigererwa, R., Mosha, F. W., et al. (2014). Indoor Residual Spraying in Combination with Insecticide-Treated Nets Compared to Insecticide-Treated Nets Alone for Protection against Malaria: A Cluster Randomised Trial in Tanzania. PLoS Med, 11 (4).

[18] WHO. (2013). World Malaria Report 2013. World Health Organization, 20 Avenue Appia, 1211 Geneva 27, Switzerland: WHO Press.

[19] World Health Organization. (2014). 10 facts on Malaria. Retrieved October 18, 2014, from WHO: http:/www.who.int/features/factfiles/malaria/en/

[20] World Health Organization. (2009). 10 Facts on Malaria in Africa. Retrieved 08 19, 2014, from WHO: http://www.afro.who.int/en/clusters-aprogrammes/dpc/malaria/features/2287-10-facts-on-malariain-africa.html

[21] World Health Organization. (2007). Implementation of Indoor Residual Spraying of Insecticides for Malaria Control in the WHO African Region Report. Brazzaville, Congo: World Health Organization for Africa.

[22] World Health Organization. (2013). Indoor residual spraying: an operational manual for indoor residual spraying (IRS) for malaria transmission control and elimination. WHO.

[23] World Health Organization. (2006). Indoor residual spraying: Use of indoor residual spraying for scaling up global malaria control and elimination, WHO position statement. World Health Organization.

[24] World Health Organization. (2014, March). Media Center: Malaria. Retrieved 08 18, 2014, from WHO: http:/www.who.int/mediacentre/factsheets/fs094/en/

[25] World Health Organization. (2010). World Malaria Report: 2010. World Health Organization, 20 avenue Appia, 1211 Geneva 27, Switzerland: WHO Press.

[26] World Health Organization. (2011). World Malaria Report: 2011. World Health Organization.

[27] World Health Organization. (2013). World Malaria Report: 2013. World Health Organization, 20 Avenue Appia, 1211 Geneva 27, Switzerland: WHO Press.

[28] World Helath Organization. (2014). Review of current evidence on combining indoor residual spraying and longlasting insecticidal nets. Retrieved November 29, 2014, from http://www.who.int/malaria/mpac/background. 